\title{
Advocate and Survivor Perspectives on the Role of Technology in Help Seeking and Services with Emerging Adults in Higher Education
}

\author{
Rachel Voth Schrag $^{1} \odot \cdot$ Dixie Hairston ${ }^{2} \cdot$ Megan L. Brown $^{3} \cdot$ Leila Wood $^{2}$ \\ Accepted: 19 April 2021 / Published online: 13 May 2021 \\ (C) The Author(s), under exclusive licence to Springer Science+Business Media, LLC, part of Springer Nature 2021
}

\begin{abstract}
Emerging adults, aged 18-25, have come of age in a technology oriented world. The internet has been critical in mediating their personal relationships and their understanding of daily life. Emerging adults are also at unique risk of experiencing intimate partner and sexual violence (IPV \& SV) Given the increasing infusion of information communication technology (ICT) into anti-violence advocacy, and the broad use of ICT among college-attending emerging adults, this study aimed to explore how both survivors and advocates are leveraging technology for support. Using a QUAL + qual methodology (Morse and Niehaus, 2009), data were collected as part of an evaluation of campus-based advocacy as implemented in five programs. Interviews took place with 23 campus and community-based advocates, and 25 survivors of interpersonal violence who had accessed campus-based advocacy services. Additionally, 63 survivors who engaged in campus-based advocacy services responded to an online survey. Key domains identified were: 1) technology as a means of informing potential clients about services; 2) the role of technology in help-seeking, including its role in tailoring and extending the reach of services; and 3 ) the importance of recognizing technology facilitated abuse in the advocacy and education process with emerging adults. As advocacy programs are rapidly shifting to technology facilitated services in the wake of COVID-19, this study provides data on advocate and survivor experiences with technology, which can inform these changes across the spectrum of IPV \& SV services.
\end{abstract}

Keywords Intimate Partner Violence $\cdot$ Sexual Violence $\cdot$ Technology $\cdot$ Advocacy $\cdot$ Help seeking

\section{Background}

Emerging adults face unique risks for experiencing intimate partner violence \& sexual violence ([IPV \& SV], Breiding et al., 2014). Those attending institutions of higher education

Rachel Voth Schrag

Rachel.vothschrag@uta.edu

Dixie Hairston

dahairst@utmb.edu

Megan L. Brown

mlindsa3@asu.edu

Leila Wood

leiwood@utmb.edu

1 University of Texas at Arlington School of Social Work, 211 S. Cooper, Arlington, TX 76019, USA

2 University of Texas Medical Branch-Galveston, Galveston, TX, USA

3 Arizona State University, Tempe, AZ, USA
(IHEs) in the United States face high rates of interpersonal violence, with between $21 \%-26 \%$ of undergraduate women and $6-7 \%$ of undergraduate men experiencing SV, and between $14 \%-31 \%$ of women and $10 \%$ of men experiencing some form of IPV in college (Cantor et al., 2019; Fedina et al., 2018; Krebs et al., 2016; Wood et al., 2021a). With the demonstrated negative impacts of IPV and SV for college students, including diminished mental, physical, emotional, and academic well-being, colleges and universities are expanding supports to survivors. These supports have included developing campus-based advocacy services to mitigate negative impacts (Amar \& Gennaro, 2005; Coker et al., 2002; Javorka \& Campbell, 2019; Mengo \& Black, 2016; Wood et al., 2021a, b; Voth Schrag et al., 2020a).

Emerging adults, aged 18-25 are often described as digital natives, as they are among the first cohorts for whom technology has always played a critical role in mediating their personal relationships and their connection to the world around them (Coyne et al., 2011, 2013; Jensen \& Arnett, 2012; Rainie, 2012). In the years immediately preceding the 
onset of COVID-19, which precipitated a nearly over-night shift to virtual service provision within some anti-violence advocacy programs, technology and online outreach were slowly being infused into anti-violence advocacy (Brignone \& Edleson, 2019; Eden et al., 2015; Nesmith, 2018; Rempel et al., 2019; Webber \& Wilmot, 2013). Given the unique salience of information communication technologies for emerging adults, it is important to understand the experiences and perspectives of advocates and survivors within campus-based advocacy programs about working with information communication technology to navigate experiences of intimate partner and sexual violence. This takes on a unique urgency as programs face long-term shifts towards virtual service provision in the wake of COVID-19 (Peterman et al., 2020). However, little is known about the role of technology in campus-based intimate partner and sexual violence advocacy services, or the perspectives of advocates and service providers on its use in the work. Thus, the current study seeks to understand how advocates are using technology as they navigate advocacy for experiences of intimate partner and sexual violence with emerging adults, and what recommendations survivors have for the use of technology in campus-based programs.

\section{Impact of IPV and SV on Among Emerging Adults}

Emerging adults are in a distinct period of development, with a focus on continued identity development, social connection, and peer-to-peer relationships, along with informal dating, traditional dating, and committed long-term relationships (Arnett, 2000; Erikson, 1963; Jensen \& Arnett, 2012; Brown et al., 2020). Technology-based abuse, including electronic stalking, intimate partner violence via online surveillance, technology-facilitated sexual violence, and non-consensual pornography are increasingly central components of survivors' experiences of violence, particularly for emerging adults (Henry \& Powell, 2018; Messing et al., 2020). Estimates of the extent of technology based victimization among college students varies based on operationalization and sample, with studies within the United States finding between $3.7 \%$ to $40 \%$ of college students experience cyberstalking (Alexy et al., 2005; Reyns et al., 2012), with evidence of significant increases in extent and severity over the past decade (Lindsay \& Krysik, 2012; Messing et al., 2020). In a survey of 885 undergraduates findings demonstrated that $92.6 \%$ of young women who reported sexual violence had also experienced at least one form of cyber aggression (Ross et al., 2019).

For students attending IHEs, experiencing IPV and SV has been demonstrated to have specific negative impacts, including disruptions to peer and romantic relationships and mental and physical health impacts (Coker et al., 2002; PicoAlfonso et al., 2006; Stith et al., 2004). Emerging adults attending college also face academic disruption, reduced GPAs and other academically-focused impacts (Brewer et al., 2018; Jordan et al., 2014; Voth Schrag et al., 2020b; Voth Schrag et al., 2020c; Wood et al., 2020a). For survivors of IPV, academic impacts are partially driven by school sabotage, a set of coercive controlling behaviors aimed at undermining a person's academic achievement, and thus, their future economic power (Voth Schrag et al. 2020b; Voth Schrag \& Edmond, 2017).

With significant impacts of IPV and SV that can reverberate over the life course, student-survivors need support to address these issues that are unique to their developmental stage and experience as a student (Wood et al., 2021b). Emerging adults are focused with identity development and relationship formation outside of the family of origin, so violent or abusive intimate relationships are bound to have unique long-term impacts for these individuals (Brown et al., 2020). To provide this support, advocacy services based on community models have been implemented on college campuses in the United States (Brubaker \& Keegan, 2019; McMahon \& Stepleton, 2018; WHTFPSSA, 2014; Wood et al., 2021b). Community based advocacy programs address the needs of survivors related to safety, well-being, and economic stability (Constantino et al.. 2005; Haj-Yahia \& Cohen, 2009; Lyon et al., 2008; Sullivan \& Bybee, 1999; Sullivan \& Goodman, 2019; Tiwari et al., 2010; Zosky, 2011; Wood, 2015). These services are based in traumainformed and survivor-centered care models, aiming to mitigate the impact of deleterious trauma and enhance survivor empowerment (Campbell, 2002; Davies \& Lyon, 2014; Goodman \& Epstein, 2008; Sullivan \& Goodman, 2019; Wood, 2015). Campus-based advocacy similarly is focused on survivor-centered safety, health and academic needs (Voth Schrag et al., 2020a). Campus-based advocacy may also involve the use of technology to facilitate helpseeking and service delivery.

\section{Technology, Emerging Adulthood, \& Anti-Violence Services}

The proliferation of internet and smartphone use has changed the way people communicate and how individuals build personal relationships. Life course theory suggests that the experiences of cohorts of individuals are influenced by the historical context within which they are developing (Elder, 1998). The onset of ICT as everyday social practice has shaped emerging adults' experiences of relationships, including violence, coercion, and control within relationships (Brown et al., 2020; Dragiewicz et al., 2018). Jensen and Arnett (2012) point to the use of information communication technologies as not only a new experience for millennials and Generation Z, but a contributing factor to the categorically different developmental stage of emerging 
adulthood. They argue that what some have identified a prolonged adolescence into the twenties is in part created by technology. Emerging adults now embody hybrid identities, constructed of multiple cultural influences and experiences that are afforded through online networks and social media. Social media is an important component of peer-to-peer relationships for current emerging adults, who use it to navigate social priorities, commitments, and relationships essentially gathering crucial social information from peers when they interact online (boyd, 2014; Russett \& Waldron, 2017). Over the past ten years, empirical research has documented that emerging adults are the age cohort most connected to social media and information communication technology use. The PEW Social Media Factsheet of 2019 shows that from 2005-2019 the 18-29 year old demographic group in the United States consistently led as the highest users of social media (PEW Social Media Factsheet, 2019). One study reported that $100 \%$ of emerging adults enrolled in college use the internet and spend a minimum of $3.5 \mathrm{~h}$ using social media, the internet, and a cell phone each day (Coyne et al., 2013; Jones, 2002). Given this context, all services aimed at college students and other emerging adults should carefully consider the role of technology in their efforts.

Emerging research seeks to understand the use of mobile and web-based apps to support survivors of violence or prevent future violence (Merolli et al., 2014). A 2015 survey of youth preferences for crisis counseling found that, although telephone was the single most preferred option (41\%), all forms of new media (text, chat, and social networking) taken together were more popular than traditional outreach (59\%) (Budinger et al., 2015). Prior research also shows that online interactions may create a "disinhibition effect" that allows for greater self-disclosure among youth in crisis (Budinger et al., 2015) and youth are also more likely to include discussion of difficult or distressing issues via chat or text (Glasheen et al., 2016; Haner \& Pepler, 2016).

A systematic review conducted by Rempel and colleagues (2019) identified 11 online interventions targeted at survivors of IPV, including apps providing information about safety planning, information, and support. An overarching theme among the online interventions was a focus on providing information to increase safety during relationship dissolution, as opposed to providing support over time. Similarly, Brignone and Edleson (2019) identified 38 apps for the iPhone that have been developed to support survivors of IPV, finding evidence that the apps rated most highly by survivors and advocates were developed in collaboration between advocates and other professionals. The use of technology to mediate direct service provision for survivors has been examined in studies focused on health care and counseling settings. Tarzia and colleges $(2016,2018)$ found that interpersonal support for survivors in health care settings can successfully be delivered interactively online, although challenges exist in the building of trust and rapport which may hinder disclosure for some survivors. Similarly, Hassija and Gray (2011) found that it is possible to use video conferencing to provide mental health support to survivors in rural areas. However, to this point, much of the research on the use of technology to support survivors of IPV and SV has focused on the development of apps or other interventions, rather than the use of technology to mediate and facilitate the advocate - survivor relationship (Brignone \& Edleson, 2019).

\section{The Current Study}

Given the unique salience of information communication technologies for emerging adults, it is important to understand the experiences and perspectives of advocates and survivors within campus-based advocacy programs about working with information communication technology to navigate experiences of intimate partner and sexual violence. This takes on a unique urgency as programs face long-term shifts towards virtual service provision in the wake of COVID-19 (Potter et al., 2020). Thus, this study asks two questions: How were advocates using technology with emerging adults who are survivors of intimate partner violence and sexual violence in the year immediately preceding the COVID-19 pandemic? and; What are survivor recommendations for advocacy and service engagement via technology? Data from this study also provide survivor and advocate voices related to service modalities that are currently undergoing major shifts due to the COVID-19 pandemic.

\section{Methods}

\section{Participants}

Participating advocates $(n=23)$ ranged in age from 28 to 64, and 19 identified as female. Slightly under half identified as Latinx, Black, or multiracial $(n=10)$ with the rest identifying as white, and most $(n=16)$ had master's degrees in social work, psychology, education, or similar disciplines. Most service users who participated in qualitative interviews $(n=25)$ were students on the participating campuses at the time of the interview, and ranged in age from 18-27. Fifteen survivor participants identified as heterosexual $(n=15)$, with other identifying as asexual, bisexual, pansexual, queer, or questioning. Fourteen participants identified their race as white and 9 identified as other races including Black, Latinx, Asian, and multiracial. 63 participants in the pilot survey, $86.3 \%$ identified 
as female, over $60 \%$ identified as people of color, and approximately $30 \%$ identified as LGBTQIA.

\section{Study Procedures}

Data were collected in the Spring and Summer of 2019 as part of an evaluation of campus-based advocacy as implemented in five programs within three universities in a single state in the American Southwest. These universities included an urban research university, a selective state flagship, and a research university with campuses along with U.S./Mexico border. Programs were housed within a student counseling center, within student affairs, within campus law enforcement, and as a stand-alone campus unit. Qualitative and quantitative data streams were collected concurrently. Qualitative data were collected from complimentary populations- campus and community-based interpersonal violence advocates who work with campus-based survivors, and survivors of interpersonal violence who had used campusbased advocacy services. Quantitative data were collective via web-survey from campus-based advocacy program service users. Using multiple, and distinguishing groups (QUAL + qual) contributes to the strength of qualitative data through triangulation between data streams, which leads to both convergence and divergence among groups (Morse \& Niehaus, 2009).

Twenty-three advocates were recruited to participate in the study. In total, 15 campus-based advocates working within the five partner programs, and 8 community advocates from agencies that are housed within the geographic regions surrounding the participating Universities, and who were suggested by campus-based advocates or professional contacts based on their known work with college students, were interviewed. Community-based advocates all worked in programs with standing relationships with the campusbased advocacy programs. Advocates were eligible to participate in qualitative interviews if they were over 18 and had professional duties including advocacy, case management, counseling, safety planning, and/or supportive services with college-aged emerging adults who identified as survivors of IPV and/or SV. All advocate interviews lasted between $45 \mathrm{~min}$ and an hour and occurred in locations of the participants' choice. Community based advocates were interviewed along with campus-based advocates in situations where community anti-violence agencies had formal or informal relationships with campus programs aiming to support survivors living on and off campus, and because an aim of the broader study was to understand advocacy modifications for the campus setting.

Qualitative interviews were also conducted with 25 survivors of interpersonal violence and who had accessed campus-based advocacy services in the past two years. Participants were recruited via e-mails coming from the participating campus advocacy programs. The email contained information about the study, contact information for the study team, and information on how to participate. Additionally, promotional materials (flyers, social media blasts) were provided to partner programs and displayed in appropriate locations. Interviews were conducted in person by trained qualitative interviewers all of whom had previous experience working with survivors of interpersonal violence. All interviews were conducted in private locations of the participant's choice, and they were recorded with participant permission. Survivors received a $\$ 20$ incentive for participating in the interview, which lasted between 30-60 min. The study employed a distress protocol that included the ability to provide referrals to on and off campus victims services, and all interviews were conducted by researchers with substantial practice and/or research experience with survivors of violence.

The interview protocols for each group included questions to illicit participants' experience with and perceptions of campus-based interpersonal violence advocacy. Questions for advocates included demographics, professional licensure and experience, services provided, differences between campus and community-based work, specific items related to how they engage with survivors, including items directly querying their use of various forms of technology (e.g., "Do you use technology in your work with survivors? (query: Text messaging, apps, MyPlan, email, phone, etc.) their goals for advocacy with survivors, and perceived impact of advocacy on survivors. The service user interview protocol was structured similarly, and aimed to understand user experiences with and perceptions of campus-based advocacy, as well as how they seek help for violence in the collegiate context, with explicit prompts about use of technology and the internet (e.g., "Since you stated working with [advocate], on average, how many times a week would you say they talked to you on the phone/text/email"). The interview protocol was adapted in part from the Community Advocacy Project fidelity evaluation (Sullivan, 2016).

Additionally, a pilot quantitative fidelity and impact survey was completed via web-based survey by 63 survivors who had previously accessed advocacy services. Participating programs sent recruitment information including the survey web-link to eligible survivors who had used services in the past 6 months. The survey focused on the advocacy process as well as key outcomes of advocacy, and was adapted from the CAP fidelity survey (Sullivan, 2016). It includes questions related to service engagement, services access, and standardized measures to asses key advocacy outcomes including health, safety, and academic outcomes. Specific to 
this study, students were asked about how they learned of the program, and the form (e.g., in person, via e-mail, via text, via web conference platform) and duration their work with the program. Included in the current analysis are questions related to duration and method of service access and engagement, including frequency of engaging with advocates via specific virtual platforms or devices. Items included in the current analysis asked about the ways students learned about program services, with options including web or digital referral, and an item asking about the frequency of engagement with advocacy services via technology, including e-mail, text, or web conference. Prior to dissemination, the survey was reviewed and modified through a series of focus groups and interviews with campus-based advocates and student survivors. All study procedures were approved prior to the commencement of data collection by the institutional review board of the sponsoring university.

\section{Data Analysis}

A qualitative content analysis approach was employed by the first, second, and fourth authors, which aimed to summarize and describe the data (Elo and Kyngäs, 2008; Sandelowski, 2010). Initially, Audio recordings were transcribed verbatim and transcripts, along with memos, were reflexively analyzed to identify patterns and descriptive codes related to the experience of survivors and advocates in advocacy services, and their engagement with technology as a means to access or facilitate the receipt of support for experiences of interpersonal violence. From this review, a second level of coding entailed organizing these categories and concepts into a codebook outlining key categories and domains, which was developed from the dataset and refined by a team of three researchers (Graneheim \& Lundman, 2004). Data were then coded line-by-line by three members of the team, with regular meetings to discuss and review themes. Interrater reliability for qualitative themes (Kappa values) ranged from 80.48 to 100 among coders. The final codebook had 13 codes and 29 sub-codes. Memoing was a regular part of the coding process and used to define and name themes during line-by-line coding. Those themes were discussed with a fourth research team member who is also an advocate practitioner as a type of member check. For the current study, codes related to technology $(n=3)$ were further analyzed by the first and second author for additional nuance.

Along with qualitative data, quantitative data from the pilot survey provides insight into the role of technology in advocacy with college-based emerging adults. Descriptive analysis was used to identify the frequency of reported services engagement through technology (phone/text/e-mail/ secure message), as well as the number of students who first learned of advocacy services via the program's website.

\section{Findings}

\section{Overview}

Survivors and advocates talked about engaging through a wide range of technology, including phone, text, secure message, and online resources. Email, phone, text, and secure message are commonly used to communicate with students to coordinate appointments, send referral information, and engage in safety planning. Students reported experiences of online harassment/stalking through email and social media outlets as well as non-consensual distribution of intimate images. Three key categories were identified when examining how technology is used in advocacy with emerging adults who are survivors of intimate partner violence and sexual violence: 1) Advocates viewing technology primarily or partly as a strategy for informing students and campuses at large about available services; 2) Advocates and students using technology as a means of seeking help, through information gathering, in service seeking, and to tailor and extend the reach of services; and 3) Advocates reflecting on the importance of addressing technology facilitated abuse in their campus-based work. Additionally, a number of recommendations were shared by survivors for the effective use of technology in advocacy services, including: the importance of quick responses in technology facilitated processes; the importance of thinking about the packaging and messaging of technology facilitated interfaces to enhance personalization and warmth; and the role that technology can play in educating emerging adults about healthy and unhealthy relationships and the process of seeking help. Each of the three primary categories among advocates and survivors are discussed, with a final presentation of direct recommendations from survivors.

\section{Category 1: Advocates Using Tech to Inform Students and Campuses.}

On-campus advocacy professionals frequently discussed relying on social media to 'get the word out' about their services. Having an active social media and web presence was a priority for many of the interviewed advocates, although their comfort with the modality of engagement varied considerably based on their programmatic structure (for example, institutional location or rules around confidential status). Further, many programs identified social media engagement as very desired, but difficult to implement for a number of reasons. Some programs faced serious barriers to social media engagement because of institutional rules around such activity, while other identified challenges related to managing social media as a primary barrier. One program 
leader reflected on trying to balance the benefits of social media with drawbacks in terms of time and dealing with comments, stating:

I mean, for the most part, we try doing social media. We try doing any type of social media that we can. I don't wanna dabble too much into the social media because it can become time-consuming and I don't wanna deal with the craziness that goes on with, sometimes, social media and the comments and stuff like that. I do, myself, try to limit it. We try to just do the popular ones, which are Facebook and Instagram.

Several advocates noted that some of their initial engagement with survivors comes via social media. For example, one advocate shared:

We do communicate. We have a lot of people-a lot is an overstatement. We do have people who find us through Facebook or through our website. We try to do a lot of social media... Apparently, we have a Twitter now.

The extent to which social media or technology serves as a 'virtual front door' to services varied among programs. One program, with the greatest amount of digital engagement, also provides a direct portal to request services via their university-sponsored website, allowing survivors to self-schedule services. An advocate shared that " $[$ on] the website there is an opportunity for our folks to request an appointment online and so, they can fill out a form." This was seen as a major benefit for students and advocates alike, allowing them to mentally prepare for an initial session, and taking away some of the anxiety about the first interaction, as it can be done in comparative anonymity.

Along with facilitating service seeking, advocates talked about structuring their digital presence to answer questions and underscore the inclusivity of their services. One advocate shared that:

We got a shit-ton of questions about LGBTQIA, which is why we started gearing more-which is why we put up stuff on our website that addresseswhat do these letters mean? We had a lot of questions about that. We tried to modify some of the things that we do based on the things that we gathered as questions our students have.

One campus-based advocate shared their strategy for using technology to reach out to students after a Title IX investigation has been reported. They stated:

We have just a standard email that has a lot of Title IX resources that we send to that, and also just is offering to meet or talk further. We really just put it in the student's court to respond or not respond.

In examples like this, advocates are clearly balancing active 'recruitment' of survivors into services while valuing the survivor-driven voluntary services model that is frequently seen in community-based advocacy, where the choice to engage in services is wholey in the hands of the survivor (Wood et al., 2020b).

\section{Category 2: Technology as a Means of Help Seeking}

Survivors Using Communication Technology as they Seek Help Survivors spoke frequently of the role of technology in their decision-making process related to engaging with advocacy services. However, of the 63 respondents to the pilot survey, only 7 (11\%) reported first learning about the advocacy program via the program or institutions' website. This route for finding out about services was illustrated by a survivor who shared in an interview that "I found out about [the advocacy program] by mainly a Google search. Nobody really told me about it. I think that's one of the big pitfalls actually, is that it's so difficult to know about the resources here." While this way of learning about services seems to be comparatively rare, survivors frequently spoke about exploring a programs' web presence to learn more about the program and available services prior to seeking help. Many survivors checked out the program's website or social media in an attempt to understand what the process of receiving services from the program was like, what they could expect, and what would be expected of them. One survivor shared that they appreciated the information they found online, stating, "I think it was pretty well detailed on the website. Oh, you're just gonna go talk to somebody and then they'll set up something for later, whatever." Several survivors also talked about being pointed to services via e-mail, after having made a report to Title IX or another campus entity. While survivors initially found out about the existence of services from a wide range of sources, including friends, websites, tabling events, and orientation activities, nearly all survivors discussed going to the program website or Facebook page to find out more about the services, if they were eligible for services, and what engagement with services might be like. Many survivors also talked about using web searches as one step in their help seeking process. One student specifically reflected on using the website to understand the process of seeking help confidentially. They found specific, technical information especially important as they student learned about options for reporting without having to engage with the Title IX process, stating that they looked at each potential resource to see if they could discern which programs would try to make them report to Title IX and which would not. Importantly, they were looking for 
indicators not only of a mandate to report to Title IX, but also a feeling, or sense, that the program might put pressure on them to report, even if they wouldn't 'mandate' it.

\section{Use of Technology in Service Provision/on-going Care Along} with facilitating the initial engagement of survivors into campus-based advocacy services, survivors and advocates also reflected on the use of various information communication technologies for on-going advocacy work. Of the 63 survivors who participated in the pilot survey, 27 survivors $(43 \%)$ reported using technology (phone, text message, e-mail, or secure message system) to connect with their advocate more than once. Of these $27,26 \%$ reported communicating via technology with their advocate more than 8 times, $26 \% 6$ to 7 times, and $26 \% 4$ to 5 times. Importantly, in this pre-COVID sample, very few survivors or advocates discussed using video conferencing or formal tele-health platforms for service provision. Advocates who were interviewed varied widely in their comfort with and endorsement of information communication technology in their advocacy work with students. On one end, one advocate shared that they used e-mail, phone, or secure message "pretty much just for appointment reminders," while on another, an advocate shared that:

Probably half, at least, of my interactions with our clients are via email. My cell phone is a working phone because the university pays for part of it [laughter] and because our office phones boot to this when-if you stay on our lines and you need something, it boots to my cell.

One survivor who participated in an interview shared that their advocacy experience was entirely mediated by information communication technology, stating:

I don't think I actually ever met her in person. It was just the conversations we had over the phone. Then we had emailed back and forth until everything was signed, because she had told me my options about like a no-contact initiative or something. It was really mostly over email.

While these reflect the extreme cases, most survivors and advocates reflected on a hybrid approach to interaction, with some digital interface supporting the in-person advocacy and support.

Tech as Means of Tailored/survivor-centered Care For advocates who were more comfortable with using communication technologies, they often spoke of them as a strategy for tailoring their services to the specific needs and circumstances of the survivors they were working with. One advocate talked about trying to tailor their tech engagement based on the safety needs of the survivors they are working with, sharing:

Sometimes partners will have access to the secure message or may have the ability to access that information. That is another aspect of the safety plan that I do in all my sessions, is, 'What's the best way to communicate with you?'

Similarly, an advocate shared:

I tend to stick mostly to - well, it really depends on what is safe for them, what's the best way for them to communicate. If they are in a DV relationship and they have access to their emails, that may not be the best way to reach out to them. I kinda leave it more towards the individual, what's best to contact them.

Another advocate talked about making different choices related to technology based on the seriousness of the violence situation, and providing additional forms of potential communication for survivors in the highest risk situations. They stated:

I have given out my personal cell phone from time to time, but that is not in every student crisis situation. I'm very picky and choosy on, I feel like the student and I need to know when contracting for safety. Also establishing that trust, because I can tell they're so hesitant to either take the emergency housing when I know that they do not need to go back to that situation. Just allowing to know, I even have that form of communication with that student, but I also know that you're crossing boundaries quickly on the type of work that we do. Again, it's pick and choose. Yes, so email, texting when appropriate, and that's really it.

As evidenced in these and other interviews, advocates were clear in the need to constantly consider the drawbacks and risks as well as the benefits of each mode of communication carefully.

Tech to Increase Advocate Reach Along with these active strategies for engagement using technology, several advocates talked about the availability of technology as a form of passively being available based on survivor needs or to address emergent situations. This allowed them to extend their engagement engage with and response to survivors. One advocate illustrated the way that technology provided them a way of being available as needed, stating:

[It is] a little bit of both, depending on the person or depending on the situation. They know my email. I'll give them my business card and say, "This is my business card. You can email me at any time if you have any questions or anything like that. You have my office 
line." If it's a little more serious, when it comes to the stalking, I will give them my work cellphone.

Another advocate shared that:

We do a lot of phone calls and really within the campus environment one thing that I've found that's different than in other settings is email is actually pretty effective and helpful. Not always, but I find myself doing a lot more email communication then I have in any other setting.

Advocates felt that providing a range of contact options allowed them to project a sense of availability and supportiveness, which was seen as a major advantage. However, they also saw the drawbacks.

Concern About Confidentiality and Boundaries. While advocates nearly universally acknowledge the important role of technology in the lives of emerging adults, and many used a variety of information communication technologies in their advocacy work, advocates also shared significant reservations about any engagement strategy that might pose risks to confidentiality, survivor safety, and advocate boundaries. As an advocate shared, "Occasionally [we text], we try to avoid that for confidentiality and boundary reasons, but yes that has been a thing." Another advocate talked about trying to encourage specific, safe forms of technology facilitated communication, and using technology as a bridge to face to face services, saying: "I mean, our email, for the most part, is secure, for the most part but Facebook Messenger is one of those that I don't like discussing stuff. I always try to tell them, "We're in the office. Come see us," or "Call us to this number. We'll talk to you." Advocates also talked about the limits to their accessibility via technology, with one sharing that:

We have an on-call phone. We usually try to keep that to just the officers having that phone, but sometimes, for very specific reasons, clients need access to that number and that phone. We've used that before too. Keeping the boundary very-I'm not giving anyone my own phone number, but we do have a department issued phone that we can use to communicate.

Along with boundaries, advocates shared anxiety about the security and confidentiality of certain forms of communication, especially those that could be requested via the Freedom of Information Act, or otherwise accessed. One advocate shared "Well, first of all, we don't use email, and the reason for that is just because we're public employees, so our email is public record, and so we don't really ever want client information in the email." Some anxiety about electronic communication due to their status as public employees of state owned institutions which could have their records requested was echoed by several advocates.

\section{Category 3: Advocates addressing Technology Facilitated Abuse}

Along with discussing how technology is used in services, many advocates pointed to the fact that, with emerging adults, their job entails supporting victims of technology facilitated abuse, and helping survivors safely engage with technology. One advocate reflected on the way evolving digital media trends shifted quickly even within generational cohorts:

Something as simple as [technology] sometimes we don't even think about, especially 'cause Gen Y, Gen Z, I'm a millennial, but even then, I see how people use social media, and I'm like, geez, I'm nowhere near that. So even this new generation, younger generation not even that far apart from my age, just a couple years, just the way they consume things and use social media so differently.

A significant part of keeping pace with online trends is in part helping survivors incorporate new practices that will promote safety during their healing process. Advocates frequently referenced technology safety strategies as an important part safety planning discussions. One shared: "It's normalcy and letting them [survivors] know just even things like have you checked your social media settings?" Another had a similar perspective "It's keeping that aspect also into - let's talk about social media settings. Let's talk about your Facebook. Are you posting anything public? Should we change those settings? Do you feel comfortable?" Advocates reflected on addressing technology and its role in violence as a central part of safety planning, and core to their advocacy work. One advocate shared:

If the other person had their information for banks, emails, you go over passwords, posting, getting rid of everything, being careful who you hang out with, who you tell. Then there was another case where the little girl changed her phone number four to five times. Every time, he kept getting it, and she would only give the number to her immediate family and two friends... Have you gotten your car checked, your phone checked for any kinda trackers?...Just also if you're out with friends, don't get in their pictures just in case...It is a small world, so sometimes people's profiles aren't private, so making them understand like, "Yeah, okay, so you're at the bar or the movies or whatever and you're posting right away. Then he sees that." 
This advocate and other underscored that their role as not only to address current risks related to technology-based abuse, but also to educate and train survivors to be aware of the ever-evolving ways that technology comes into play in safety.

\section{Survivor's Tech Focused Recommendations For service Providers}

As part of the larger evaluative effort, survivors were asked to reflect on the way that programs used technology, and how they could enhance their services. Their responses included feedback related to the speed of services provided via technology, feedback related to the importance of maintaining warmth and a sense of empathy even when interactions mediated by technology, and encouragement to explore the potential role for technology in healthy relationships education with emerging adults. While not all of these recommendations were widespread across interviews, they all reflect the suggestions which could be generally useful.

\section{Recommendation: Quick Responses Matter to Survivors, Regardless of the Medium}

Some survivors emphasized their expectations that having technology to facilitate communication with programs should lead to faster services and quicker resolutions, but that this was not always the case. One survivor talked about her experience with campus representatives and emails involving her situation:

That incident happened in June, and I didn't start getting emails from Title IX until September or August. By the time [the program] finally reached out to me it was a long time, and I'd pretty much come to closure on the issue by myself... They sent me some funky emails, and then I got some letter saying that the issue was resolved-some email letter saying the issue was resolved. That's just awkward. I don't really know what kind of ping pong they did from Title IX to the Dean's office and whoever else, but it didn't really involve me.

The sense that 'funky e-mails' were sent several months after the fact, rather than quickly after the report was made, was a source of additional betrayal for the student, where a quick electronic contact could have set them on a different trajectory including the use of services. Other students reported similar experiences in which the delayed response from institutions or advocates was a substantial disappointment, and seemed the more unfathomable because of the perceived ease of 'just sending an e-mail.'

\section{Recommendation: Warmth and Tone Matter even in Technology Facilitated Services}

A number of survivors reflected on the importance of feeling like there was a caring and responsive person still connected to the services they were accessing via communication technology. One student illustrated what this could look like in an inital e-mail, saying:

Yeah. Instead of like, "We are the [advocacy program] here to get into your personal business." An individual-it's like, "Hi. I'm so-an-so from [advocacy program]. I heard about your situation. Would you like to schedule a time to talk? I'm interested in helping you process your situation."

Another student talked about the impact of calling the after-hours hotline number provided by the larger university umbrella organization under which the advocacy program was housed, to hear a sad romantic love-song being played as the 'please hold' music while their call was forwarded to an on-call staff person. They shared that this disconnect between the trauma they had just experienced and the seemingly tone-def hold music was distressing for them, and caused them to doubt the usefulness of the services that they might receive.

\section{Recommendation: Technology can be an Important Aide for Educating Emerging Adults about Healthy Relationships and the Process of Help Seeking}

One survivor noted that a video or app display that provided information on healthy and unhealthy relationships and warning signs would have been very useful, as would more accessible information on how to work with service systems to get help. They shared that "They make you do alcohol education at orientation. I'm sure they could throw in like a five-minute video about this." Similarly, another survivor noted that having more accessible information about systems and processes would have been very helpful to them, asking for resources to be readily available on a website or FAQ:

Just like I know that there were so many things that I had to work so hard to get to like even to just know that they were a thing. I didn't know I qualified for a protective order. I lived in that same house for like a whole month, and I was terrified the whole time.

Survivors consistently identified a need for easy to understand the easy to access information that could help them understand their options, and the risks that pursuing various pathways may pose. 


\section{Discussion}

Study findings identified dynamics surrounding the use of technology with collegiate emerging adults survivors of intimate partner violence and sexual violence in the year immediately preceding COVID-19, as well as recommendations from survivors around the use of technology in advocacy services. They also organically pointed to the role of technology in students' experiences of intimate partner and sexual violence, highlighting the importance of engaging with technology both to increase access to services and contact with advocates, and also to support survivor safety planning around technology based abuse. Emerging adult survivors are savvy and pro-active consumers of information technology to facilitate help-seeking. Many survivors reported help seeking via campus online resources. Whether it was a first step or after speaking with a campus representative or peer, their process usually included combing through a programs' website to decide about service engagements to strictly online safety planning during their duration of services. Programs need to carefully consider their web and social media presence and integrate low-barrier connection strategies using these platforms. Importantly, while many survivors learned initially of services through face to face or peer communication, their decision making about taking the next step and seeking services frequently included online research about the program. Controlling what students find out at that point in the process could have important implications for facilitating help seeking and support for students. Campus based advocacy programs can incorporate tailored messaging about their services and availability into Apps like myPlan, uSafeUS, and other platforms targeted at college students (Eden et al., 2015; Potter et al., 2020; Rodriguez-Rodriguez \& Heras-Gonzalez, 2020). Survivors are eager to understand the process of advocacy, and what a visit to the program will be like. Every visit to a site is an opportunity to engage a survivor in services and connect them with an advocate. Having content that easily directs survivors to services can be complimented with information about evidence-based tools for assessing relationship abuse, information about healthy relationships, and if applicable point site visitors to peer-based programs for connecting with other students.

Integrating an understanding of technology based abuse, and strategies to help survivors develop safety plans within virtual environments, is a critical component of advocacy work with emerging adults. These emerging adults face high rates of exposure, as young women are particularly common targets of technology facilitated abuse (Pew Research Center, 2014). Further, multiple studies have linked online harassment to poorer mental health outcomes including presenting symptoms of anxiety, PTSD, feelings of anger, and health outcomes such as loss of sleep (Dreßing et al., 2014; Maple et al., 2011; Lindsay et al., 2016). Advocates need to be prepared to help young people address technology-based abuse, and also contextualize the behaviors of perpetrators so they do not dismiss signs of escalation (Messing et al., 2020).

It is also evident that advocates are working to adapt service models to incorporate technology, but that this adds additional work to an already strained load. While service providers were readily incorporating technology to enhance their services and provide tailored survivorcentered care, this was individual and often taken caseby-case. Advocates expressed a desire for more formal training on best practices. They navigated a complicated balance of being available to clients and setting appropriate boundaries. Anxiety around these practices was also clear, related to risks to privacy, confidentiality, and safety stemming from the use of technology, and coming out of long-held fears within the interpersonal violence prevention and intervention workforce. Institutions of Higher Education often have secure digital communication methods already in place; with the right amount of institutional backing advocates could build their services to incorporate already licensed tool without needing a large infusion of cash. Comparatively, some communitybased advocates are already focused on service provision via tech (remote work, mobile advocacy, and using tech to facilitate engagement) and could provide a model for campus services (Gray et al., 2015; Tarzia et al., 2018, 2016). With the onset of technology into everyday social life, these adaptations should consider the ways in which technologies are relational and changing (Baym, 2015). Even advocates who self-identified as being "young" noticed generational differences between their experiences and those of emerging adult students. As preferred social media platforms shift, advocates must keep up with changing trends, while still staying engaged with older or less of-the-moment digital spaces, creating significant work and requiring ongoing assessment of the preferences of students on their specific campus. Including questions about which social media platforms students are using, and how they learned about advocacy services, on annual or semi-annual service evaluations could help advocates keep up with changing patterns and preferences. Being digital natives themselves did not prevent advocates from identifying the amount of effort and labor needed to curate content for digital outreach. Social media pages are significant for connecting students to services, but no advocates mentioned allocated resources for professional management of these pages.

Survivors also had a number of specific recommendations for advocates seeking to roll out or continue online services, often focused on how to ensure rapport, 
engagement, and support between survivor and advocate remain the foundation of advocacy relationships. Survivors were clear that one of the advantages of technology mediated advocacy service engagement is the ability to receive rapid information or feedback. However, when survivors who are used to the immediacy that engagement over technology provides experienced delayed responses, especially delayed responses that are then mediated through technology, this added to a sense of institutional betrayal, diminishing trust between survivor and advocate (Smith \& Freyd, 2014). In line with Smith and Freyd's (2014) definition of institutional betrayal, failures to quickly follow up on digital reports of violence, or on other digital outcries or requests, were offered as examples of institutional inaction that exacerbated the impact of trauma for service users.

\section{Limitations}

This work has several key limitations. First, all the participating advocates and service users were from within the same university system, and all from the same southern state. Included programs work within a range of institutional locations and on campuses with different cultures and climates, however all campuses and programs are in the context of public institutions. Future work should explore the experiences and needs of advocates and service users in smaller public institutions, at private institutions, and within community-college settings. Additionally, this work was specifically with those over the age of 18 and enrolled in higher education, but technology facilitated abuse is a serious issue for all emerging adults. The role of technology in advocacy with non-IHE attending emerging adults should be closely examined to understand the needs of this important population. This work came from within a larger campus-based advocacy evaluation focused on services efficacy and process. Greater attention to technology use in the interview guide may have resulted in additional detail or more themes being identified. Finally, while service users reflected a range of experiences (positive and negative) with the programs themselves as well as with the universities more broadly, all were recruited through participating advocacy programs. Thus, they may include more students with positive advocacy experiences who opened the recruitment email and were interested in engaging with the study team.

\section{Implications}

Campus-based advocates, and other IPV and SV advocates, are rapidly shifting service provision modalities to respond to COVID-19. With students sent home and campuses empty, virtual services have become a crucial lifeline for campus-based programs to maintain support and safety. As shifts in service provision modalities continue to unfold in the COVID-19 era, understanding the experiences of advocates and survivors with using technology as a part of interpersonal violence advocacy services can enhance the efficacy of these critical tools. Campus based survivors are clearly open to engaging in advocacy services through technology- both for services coordination and for service delivery. While there was little use of video-conferencing within the five programs studied here, recent work has identified a dramatic increase in video-conferencing being in IPV and SV advocacy after the onset of COVID-19 (Wood et al., 2020c). Programs could consider using the high quality, secure, encrypted videoconferencing platforms that many IHEs have invested in for online education and to support teleworking in order to expand the range of services available to survivors. Peer support groups, educational groups, and evidence-based trauma therapies could all be delivered in this format, expanding their availability to online and distance students, as well as creating opportunities for universities to partner to provide certain tailored therapies (Gray et al., 2015).

Survivors also encouraged programs to think about the overall presentation of services that are mediated through ICTs, and how that sets up the survivor to experience the service. One example a survivor provided was not to play a love song as the 'hold music' on the centers' answering machine. They were also clear that advocacy programs (as well as Title IX offices and other institutional authorities) should ensure that there is easily accessible, clear, and accurate information about program processes and expectations. They noted that survivors shouldn't have to hunt through webpages of Title IX language to understanding the consequences of reporting, or to understand who is and is not confidential on campus. Similarly, attending to the accessibility of digital resources for survivors with disabilities should be a priority for programs and institutions, especially given the increased risk within this population of students. Finally, survivors and advocates alike identified the potential opportunity to use technology mediated interfaces to expand healthy relationships education on campus.

Further, these data make it clear that advocates are working diligently to incorporate technology into their services to meet the needs of college students, but they need additional resources, training, and support to maximize their efficacy. Advocates can be empowered to address specific tactics of technology facilitated abuse by learning the processes to remove images that are leaked, use password managers, and increase security for certain content by installing encryption or downloading apps. A primary focus of advocates was on social media, encouraging survivors to be less visible online. This can be an important part of a survivor's safety, but identifying other potential risk points could help further tailor survivors' safety plans to their specific needs and wants. As 
we increasingly learn about the types of technology-facilitated intimate partner and sexual abuse, it is imperative that the onus is put on the perpetrators of those actions as much as possible, rather than expecting survivors to take on the burden of adjusting their behavior. Disengaging from social media for a period of time might be an important step for some survivors, but systems should also focus on preventing and holding offenders accountable for their acts of technology facilitated abuse.

As institutions continue to build out advocacy programs, the expanding role of technology in services should be a part of their conversation, as well as a part of their budget planning. Leadership should take seriously requests for necessary technology, training, and website and social media management, as well as the importance of the digital environment in which virtual services take place. Including digital 'front doors,' where survivors can request and schedule services securely could be a helpful way of lowering barriers to service access for students. Several advocates mentioned using their own personal technology (smart phones, etc.) for communicating with survivors- through phone forwarding, social media updates, or texting. Institutions could support this sort of work through paying part advocates personal phone bills or providing these needed work supplies outright. Many IHEs have invested heavily in online communication platforms for faculty, extending access to these services to campus-based advocates could be an easy way to substantially increase the tools available to campus programs.

Funding This project was funded by the Criminal Justice Division of the Office of the Texas Attorney General.

\section{References}

Alexy, E. M., Burgess, A. W., Baker, T., \& Smoyak, S. A. (2005). Perceptions of cyberstalking among college Students. Brief Treatment and Crisis Intervention, 5(3), 279-289. https://doi.org/10.1093/ brief-treatment/mhi020

Amar, A., \& Gennaro, S. (2005). Dating violence in college women: Physical injury, healthcare usage, and mental health symptoms. Nursing Research, 54(4), 235-242

Arnett, J. J. (2000). Emerging adulthood: A theory of development from the late teens through the twenties. American Psychologist, 55(5), 469-480

Bhochhibhoya, S., Maness, S. B., Cheney, M., \& Larson, D. (2019). Risk factors for sexual violence among students in dating relationships: An ecological approach. Journal of Interpersonal Violence. https://doi.org/10.1177/0886260519835875

boyd, d. (2014). It's complicated: The social lives of networked teens. Yale University Press.

Breiding, M.J., Chen J., \& Black, M.C. (2014). Intimate Partner Violence in the United States - 2010. National center for injury prevention and control, centers for disease control and prevention.
Brewer, N., Thomas, K. A., \& Higdon, J. (2018). Intimate partner violence, health, sexuality, and academic performance among a national sample of undergraduates. Journal of American College Health, 66(7), 683-692. https://doi.org/10.1080/07448481.2018. 1454929

Brown, M. L., Krysik, J., LaMendola, W., Sinha, D., \& Reed, L. (2020). Relationship fluidity: The changing nature of intimacy for emerging adult women. In recent advances in digital media impacts on identity, sexuality, and relationships. (pp. 39-61). IGI Global.

Brignone, L., \& Edleson, J. L. (2019). The dating and domestic violence app rubric: Synthesizing clinical best practices and digital health app standards for relationship violence prevention smartphone apps. International Journal of Human-Computer Interaction, 35(19), 1859-1869. https://doi.org/10.1080/10447318.2019. 1574100

Brubaker, S. J., \& Keegan, B. (2019). "Suddenly everyone's an expert in our field": Campus victim advocates and the promise and perils of professionalization. Violence Against Women, 25(9), 11161137. https://doi.org/10.1177/1077801218807096

Budinger, M. C., Cwik, M. F., \& Riddle, M. A. (2015). Awareness, attitudes, and use of crisis hotlines among youth at-risk for suicide. Suicide and Life-Threatening Behavior, 45(2), 192-198

Baym, N. K. (2015). Connect with your audience! The relational labor of connection. The Communication Review, 18(1), 14-22

Campbell, J. C. (2002). Health consequences of intimate partner violence. Lancet.

Calderón Gómez, D. (2019). Technological capital and digital divide among young people: An intersectional approach. Journal of Youth Studies, 22(7), 941-958.

Cantor, D., Fisher, B., Chibnail, S., Harps, S., Townsend, R., Thomas, G., Lee, H., Kranz, V., Herbison, R., \& Madden, K. (2019). Report on the AAU campus climate survey on sexual assault and sexual misconduct. Westat.

Coker, A., Smith, P., Thompson, M., McKeown, R., Bethea, L., \& Davis, K. (2002). Social support protects against the negative effects of partner violence on mental health. Journal of Women's Health \& Gender Based Medicine, 11(5), 465-476

Constantino, R., Kim, Y., \& Crane, P. A. (2005). Effects of a social support intervention on health outcomes in residents of a domestic violence shelter: A pilot study. Issues in Mental Health Nursing, 26, 575-590

Coyne, S. M., Padilla-Walker, L. M., \& Howard, E. (2013). Emerging in a digital world: A decade review of media use, effects, and gratifications in emerging adulthood. SAGE Publications Inc. https://doi.org/10.1177/2167696813479782

Coyne, S. M., Stockdale, L., Busby, D., Iverson, B., \& Grant, D. M. (2011). "I luv u :)!": A descriptive study of the media use of individuals in romantic relationships. Family Relations, 60(2), 150-162. https://doi.org/10.1111/j.1741-3729.2010.00639

Davies, J. M., \& Lyon, E. (2014). Domestic violence advocacy: Complex lives/difficult choices. (2nd ed.). Sage.

Dragiewicz, M., Burgess, J., Matamoros-Fernandez, A., Saltner, M., Suzor, N., Woodlock, D., \& Harris, B. (2018). Technology facilitated coercive control: Domestic violence and the competing roles of digital media platforms. Feminist Media Studies, 18(4), 609-625. https://doi.org/10.1080/14680777.2018.1447341

Dreßing, H., Bailer, J., Anders, A., Wagner, H., \& Gallas, C. (2014). Cyberstalking in a large sample of social network users: Prevalence, characteristics, and impact upon victims. Cyberpsychology, Behavior, and Social Networking, 17(2), 61-67. https://doi. org/10.1089/cyber.2012.0231

Duggan, M., \& Smith, A. (2013). Social media update 2013. Pew Internet and American Life Project, (January), 1-18.

KB Eden NA Perrin GC Hanson JT Messing TL Bloom JC Campbell ...NE Glass 2015 Use of online safety decision aid by abused 
women: Effect on decisional conflict in a randomized controlled trial American Journal of Preventive Medicine 484372383

Elder, G. H. (1998). The life course as developmental theory. Child Development, 69(1), 1-12. https://doi.org/10.1111/j.1467-8624. 1998.tb06128.x

Elo, S., \& Kyngäs, H. (2008). The qualitative content analysis process. Journal of Advanced Nursing, 62(1), 107-115. https://doi. org/10.1111/j.1365-2648.2007.04569.x.

Erikson, E. H. (1963). Childhood and Society. (2nd ed.). W. W. Norton \& Company.

Fedina, L., Holmes, J. L., \& Backes, B. L. (2018). Campus sexual assault: A systematic review of prevalence research from 2000 to 2015. Trauma, Violence, \& Abuse, 19, 76-93

Glasheen, K. J., Schochet, I., \& Campbell, M. A. (2016). Online counselling in secondary schools: Would students seek help by this medium? British Journal of Guidance \& Counselling, 44(1), 108-122

Goodman, L. A., \& Epstein, D. (2008). Listening to battered women: A survivor-centered approach to advocacy, mental health, and justice. American Psychological Association.

Graneheim, U. H., \& Lundman, B. (2004). Qualitative content analysis in nursing research: Concepts, procedures and measures to achieve trustworthiness. Nurse Education Today, 24(2), 105112. https://doi.org/10.1016/j.nedt.2003.10.001.

Gray, M., Hassija, C., Jaconis, M., Barrett, C., Zheng, P., Steinmetz, S., \& James, T. (2015). Provision of evidence-based therapies to rural survivors of domestic violence and sexual assault via Telehealth: Treatment outcomes and clinical training benefits. Training and Education in Professional Psychology, 9(3), 235-241

Hassija, C., \& Gray, M. (2011). The effectiveness and feasibility of videoconferencing technology to provide evidence-based treatment to rural domestic violence and sexual assault populations. Telemedicine and e-Health, 17(4), 309-15

Haj-Yahia, M., \& Cohen, H. (2009). On the lived experience of battered women residing in shelters. Journal of Family Violence, 24(2), 95-109

Haner, D., \& Pepler, D. (2016). "Live Chat" clients at kids help phone: Individual characteristics and problem topics. Journal of the Canadian Academy of Child and Adolescent Psychiatry, 25(3), 138-144

Henry, N., \& Powell, A. (2018). Technology-facilitated sexual violence: A literature review of empirical research. Trauma, Violence, and Abuse, 19(2), 195-208. https://doi.org/10.1177/1524838016 650189

Javorka, M., \& Campbell, R. (2019). Advocacy services for college victims of sexual assault: Navigating complicated confidentiality concerns. Journal of Trauma \& Dissociation, 20(3), 304-323. https://doi.org/10.1080/15299732.2019.1571889

Jensen, L. A., \& Arnett, J. J. (2012). Going Global: New Pathways for Adolescents and Emerging Adults in a Changing World. Journal of Social Issues, 68(3), 473-492. https://doi.org/10.1111/j.15404560.2012.01759. $\mathrm{x}$

Jones, S. (2002). The Internet goes to college: How students are living in the future with today's technology. Pew Internet \& American Life Project.

Jordan, C. E., Combs, J. L., \& Smith, G. T. (2014). An exploration of sexual victimization and academic performance among college women. Trauma, Violence, \& Abuse, 15(3), 191-200

Krebs, C., Lindquist, C., Berzofsky, M., Shook-sa, B., Peterson, K., Doukmetzian, K., Potter, S. J., Banyard, V. L., Stapleton, J. G., Demers, J. M., Edwards, K. M., \& M. M. . (2016). Campus Climate Survey Validation Study Final Technical Report. National Institute of Justice, 1(2011), 1-35

Lindsay, M., Booth, J. M., Messing, J. T., \& Thaller, J. (2016). Experiences of online harassment among emerging adults: Emotional reactions and the mediating role of fear. Journal of interpersonal violence, 31(19), 3174-3195

Lindsay, M., \& Krysik, J. (2012). Online Harassment Among College Students. Information, Communication \& Society, 15(5), 703719. https://doi.org/10.1080/1369118x.2012.674959

Lyon, E., Lane, S., \& A, Menard. (2008). Meeting survivors' needs: A multi-state study of domestic violence shelter experiences, final report. Prepared for National Institute of Justice. Retrieved from https://www.ncjrs.gov/pdffiles1/nij/grants/225025.pdf

Maple, C., Short, E., \& Brown, A. (2011). Cyberstalking in the United Kingdom: An analysis of the ECHO pilot survey. University of Bedfordshire.

McMahon, S., \& Stepleton, K. (2018, January 1). Undergraduate exposure to messages about campus sexual assault: Awareness of campus resources. Journal of College Student Development. Johns Hopkins University Press. https://doi.org/10.1353/csd.2018.0008.

Mengo, C., \& Black, B. M. (2016). Violence victimization on a College Campus: Impact on GPA and school dropout. Journal of College Student Retention: Research, Theory and Practice, 18(2), 234-248. https://doi.org/10.1177/1521025115584750

Merolli, M., Gray, K., \& Martin-Sanchez, F. (2014). Therapeutic affordances of social media: Emergent themes from a global online survey of people with Chronic Pain. Journal of Medical Internet Research, 16(12), e284. https://doi.org/10.2196/jmir.3494

Messing, J., Bagwell-Gray, M., Brown, M. L., Kappas, A., \& Durfee, A. (2020). Intersections of Stalking and technology-based abuse: Emerging definitions, conceptualization, and measurement. Journal of Family Violence. https://doi.org/10.1007/ s10896-019-00114-7

Morse, J. M., \& Niehaus, L. (2009). Mixed method design: Principles and procedures. Left Coast Press.

Nesmith, A. (2018). Reachingyoungpeoplethroughtexting-based crisis counseling: Process, benefits, and challenges. Advances in Social Work, 18(4), 1147-1164. https://doi.org/10.18060/21590

Peterman, A., Potts, A., O’Donnell, M., Thompson, K., Shah, N., Oertelt-Prigione, S., \& van Gelder, N. (2020). Pandemics and violence against women and children. Center for global development working paper, 528.

Pew Research Center (2014). Pew Research Center Internet Data. Retrieved from https://pewreserach.org/internet. Accessed 1 July 2020

Pew Research Center (2019). Pew Social Media Fact Sheet. Retrieved from https://pewreserach.org/internet/fact-sheet/social-media. Accessed 1 July 2020

Pico-Alfonso, M. A., Garcia-Linares, I. M., Celda-Navarro, N., BlascoRos, C., Echeburúa, E., \& Martinez, M. (2006). The impact of physical, psychological, and sexual intimate male partner violence on women's mental health: Depressive symptoms, posttraumatic stress disorder, state anxiety, and suicide. Journal of Women's Health, 15(5), 599-611

Potter, S., Moschella, E., Smith, D., \& Draper, N. (2020). Exploring the usage of a violence prevention and response app among community college students. Health Education \& Behavior, 47(1), $44 \mathrm{~S}-53 \mathrm{~S}$

Rainie, L. (2012) Smartphone Ownership Update: September 2012. Pew Research Internet Project. Retrieved from https://www.pewin ternet.org/wp-content/uploads/sites/9/media/Files/Reports/2012/ PIP_Smartphones_Sept12-9-10-12.pdf

Reyns, B. W., Henson, B., \& Fisher, B. S. (2012). Stalking in the twilight zone: Extent of cyberstalking victimization and offending among college students. Deviant Behavior, 33(1), 1-25. https:// doi.org/10.1080/01639625.2010.538364

Rempel, E., Donelle, L., Hall, J., \& Rodger, S. (2019). Intimate partner violence: A review of online interventions. Taylor and Francis Ltd. https://doi.org/10.1080/17538157.2018.1433675. 
I Rodriguez-Rodriguez P Heras-Gonzalez 2020 How are universities using information and communication technologies to face sexual harassment and how can they improve? Technology in Society 62 https://doi.org/10.1016/j.techsoc.2020.101274

Ross, J., Drouin, M., \& Coupe, A. (2019). Sexting coercion as a component of intimate partner polyvictimization. Journal of Interpersonal Violence, 34(11), 2269-2291. https://doi.org/10.1177/ 08862605166033

Russett, J., \& Waldron, L. (2017). It's not real until it's on Facebook: A qualitative analysis of social media and digital communication among emerging adults in college. Social Sciences, 6(3), 74

Sandelowski, M. (2010). What's in a name? Qualitative description revisited. Research in Nursing \& Health, 33, 77-84. https://doi. org/10.1002/nur.20362.

Smith, C., \& Freyd, J. (2014). Institutional Betrayal. American Psychology, 69(6), 575-587.

Stith, S. M., Smith, D. B., Penn, C. E., Ward, D. B., \& Tritt, D. (2004). November). A meta-analytic review. Aggression and Violent Behavior. https://doi.org/10.1016/j.avb.2003.09.001

Sullivan, C. M. (2016). Measuring fidelity to the Community Advocacy Project model. Michigan State University.

Sullivan, C., \& Bybee, D. (1999). Reducing violence using communitybased advocacy for women with abusive partners. Journal of Consulting and Clinical Psychology, 67, 43-53

Sullivan, C. M., \& Goodman, L. A. (2019). Advocacy with survivors of intimate partner violence: What it is, what it isn't, and why it's critically important. Violence Against Women, 25(16), 2007-2023.

Tarzia, L., Cornelio, R., Forsdike, K., \& Hegarty, K. (2018). Women's experiences receiving support online for intimate partner violence: How does it compare to face-to-face support form a health professional? Interacting with Computers, 30(5), 433-443

Tarzia, L., May, C., \& Hegarty, K. (2016). Assessing the feasibility of a web-based domestic violence intervention using chronic disease frameworks: Reducing the burden of 'treatment' and promoting capacity for action in women abused by a partner. BMC Women's Health, 16(1), 73

Tiwari, A., Fong, D. Y. T., Wong, J. Y. H., Yuen, K. H., Yuk, H., Pang, P., Humphreys, J., \& Bullock, L. (2010). Journal of the American Medical Association, 304, 536-543

Voth Schrag, R. J., \& Edmond, T. (2017). School sabotage as a form of intimate partner violence. Affilia, 32(2), 171-187.

Voth Schrag, R., Wood, L., Hairston, D., \& Jones, C. (2020a). Academic safety planning: Intervening to improve the educational outcomes of collegiate survivors ofinterpersonal violence. Journal of Interpersonal Violence. https://doi.org/10.1177/0886260520 967162.
Voth Schrag, R. J., Edmond, T., \& Nordberg, A. (2020b). Understanding school sabotage among survivors of intimate partner violence from diverse populations. Violence Against Women, 26(11), 1286-1304.

Voth Schrag, R., Wood, L., \& Busch-Armendariz, N. (2020c). Pathways from intimate partner violence to academic disengagement among women university students. Violence and Victims, 35(2), $227-245$.

Webber, R., \& Wilmot, J. (2013). Young people seeking help for sexual assault: A question-and answer online environment. Youth Studies Australia, 32(2), 30-38

White House Task Force to Protect Students from Sexual Assault (WHTFPSSA) (2014). Key components of sexual assault crisis intervention/victim service resources. Retrieved from: https:// www.justice.gov/ovw/page/file/910266/download

Wood, L. (2015). Hoping, empowering, strengthening. Affilia, 30(3), 286-301.

Wood, L., Voth Schrag, R., \& Busch-Armendariz, N. (2020a). Mental health and academic impacts of intimate partner violence among IHE-attending women. Journal of American College Health, 68(3), 286-293.

Wood, L., Clark, D., Heffron, L. C., \& Voth Schrag, R. (2020b). Voluntary, survivor-centered advocacy in domestic violence agencies. Advances in Social Work, 20(1), 1-21.

Wood, L., Voth Schrag, R., Baumler, E., Hairston, D., Guillot-Wright, S., Torres, E., \& Temple, J. (2020c). On the front lines of the COVID-19 pandemic: Occupational experiences of the intimate partner violence and sexual assault workforce. Journal of Interpersonal Violence online first publication. https://doi.org/10.1177/ 0886260520983304.

Wood, L., Hoefer, S., Kammer-Kerwick, M., Parra-Cardona, J. R., Busch-Armendariz, N. (2021a). Sexual harassment at institutions of higher education: Prevalence, risk, and extent. Journal of Interpersonal Violence, 36(9-10), 4520-4544.

Wood, L., Voth Schrag, R., Hairston, D., \& Jones, C. (2021b). Exploring advocacy practices for interpersonal violence survivors on college campuses: Approaches and key factors. Psychology of Violence, 11(1), 28-39.

Zosky, D. (2011). A matter of life and death: The voices of domestic violence survivors. AffiliaJournal of Women and Social Work, $26(2), 201-212$

Publisher's Note Springer Nature remains neutral with regard to jurisdictional claims in published maps and institutional affiliations. 